\title{
the telling room
}

SARAH HOLLAND-BATT

\author{
Your first \\ episode, \\ not the time \\ you crawled up \\ the wall, cockroach- \\ style, when \\ between calving \\ shivers you halleluiahed and \\ darted for the Bible, \\ moaning \\ Jesus \\ Saves; but when \\ the table beckoned \\ sun creeping along it, and \\ brittle salamander dreams \\ floated into glaring wakefulness. \\ The wind \\ made insinuations-
}


a cat's howl shook down
worms from she-oaks
and they danced
like skinless
toes making
dry phutts on
limestone;
oranges
rearranged themselves, swooning,
the bowl furiously
winking
at the wax faces
of the fruits;
all the pregnant apricots
made dry chucklings on the counter.

(These were the first signs.)

Then the television

made you mistrust it.

News anchor Marlie

dropped your name in,

reporting robotic a-bomb planes

punching clouds the colour of wet

violins.

Green swarmed through the open door like an enormous locust.

Your arms were a centrifuge

of vengeful garnet,

and voices dug

into your smooth walnut brain

buried themselves in its vaginal

folds. 
The invisible (latent)

grid of television snare-wire

tightened;

and you filtered it,

culled broadcast gibberish

from the real Word,

found information beaming

from the eerie cube

pure as soaked driftwood

struggling shorewards, whittled

into true units of meaning

that poured

and spewed

and gushed out like

ejaculate-

and you drank from it

you drank from the broth of eternal epistemologies

you drank from the story of stories

and the headline was

death.

SARAH HOLLAND-BATT lives in Sorrento, Queensland, where she is poetry editor for the literary magazine Vanguard, and a freelance arts writer for localART. Her poetry has appeared most recently in Aesthetica: A Review of Contemporary Artists (UK), and Ideation. 